\title{
The Embedded Strategy of Enterprise Innovation Network Based on Knowledge Base
}

\author{
Chen Guang $\mathrm{Li}^{*}$, Zhenjun Qiu and Guihuang Jiang
}

Department of Administration Management, School of Economics \& Management, North China, University of Technology, Beijing, China

\begin{abstract}
Constructing the innovation network is an important means of breakthrough in the traditional manufacturers for the emerging e-commerce platform, based on two different levels of innovation network node, content and structure, YEATION and YOUPIN were chosen to analyse and research the relationship and between knowledge base and the embedding strategy of electric business platform enterprises to create innovation network. To put forward the knowledge base width wider, insufficient depth of the enterprise should adopt structural strategy give priority to relational embeddedness, on the other hand, enterprises of which the depth of knowledge base is deep and width of insufficient shall adopt strategy give priority to the embedding of structure. At the same time, it is proposed that platform enterprises should not adopt a single embeddedness strategy, but should adopt auxiliary embeddedness strategy in a timely manner.
\end{abstract}

Keywords: Innovation network, Knowledge base, Embeddedness.

\section{Introduction}

As Chesbrough [1] suggested the way products innovated and promoted have been undergoing a reform during the past decades, manufacturers pursuing a expansion toward higher value-add link. The traditional model of enterprises completing development, manufacturing, marketing, supply and service independently becoming more and more difficult, especially for latecomers in a network circumstance. Prior literature has developed multifarious conceptual models to illustrate the pathway, for example, the "flying geese" paradigm [2], the "imitation to innovation" transformation [3,4], among which the track from original equipment manufacturing (OEM) to original design manufacturing (ODM) and original brand manufacturing (OBM) has been one of the most interested among scholars [57]. To progress to OBM, manufacturers need to possess the skill and resource of marketing $[8,9]$.

Under innovation network background, internet companies adopt quality e-commerce, which can be seen as integrated vertical e-commerce, and achieve building industrial barriers, competitive brands, and embedding in innovation network by cultivating ODMs into OBMs. In the last decade, many quality e-commerce emerged and achieved financial returns, for instance, YANXUAN, YOUPIN, XINXUAN, JINGZAO, and so on. This paper study how

\footnotetext{
* Corresponding author: chilqzj@163.com
} 
quality e-commerce integrate and exploit knowledge base of its OBMs in embedding innovation network

This article selected YANXUAN and YOUPIN as typical quality e-commerce, aiming at contributing to the debate on the relationships between innovation, industrial dynamics and industry evolution, by analyzing the links between the knowledge-base and embeddedness.

\section{Research background}

The innovation process was defined as a search process of inventions generated from recombination of existing knowledge elements novelty [10]. In this search process, the knowledge couplings a firm can reach, which is merely a small subset of the knowledge arena, is defined as knowledge base [11]. The expansion of knowledge can be labeled as two patterns, 'widening' and 'deepening'. The former is associated with knowledge searching distally across disciplines or fields, while the latter is characterized by accumulation strategies based on the existing vertical premises. Former study reveal that depth and breadth of knowledge base are important for firm performance and innovation [12,13]. More specifically, empirical Study revealed that firms' knowledge acquisition and subsequent innovative process were significantly influenced by their knowledge base characteristic [14]. Knowledge base can be either premises and constraint of particular innovation process. Zhou and Li proposed that firms with a broad knowledge base tend to achieve radical innovation through internal knowledge sharing rather than market knowledge acquisition, while firms with great knowledge base depth are more capable of developing in opposite way [15]. Carnabuci and Operti [16] indicated that knowledge of great breadth hinders firm's recombinant reuse and improve it ability to innovate through recombinant creation, knowledge base depth influencing on the opposite way. Prior Study provides evidence regarding the relationship between change in knowledgebase characteristics and industry structure in the pharmaceutical industry [17].

Twenty years after Granovetter introduce embeddedness into social network, it has developed two main perspectives: structural and relational. Structural embeddedness shows the impact that a firm's relative position in the network has on performance. Structural Perspective emphasizes properties of ego-network (focal firm) or whole network such as structural hole [18], density [19], centrality [20], size [21]. Relationship embeddedness reflects the degree of trust and information exchange between two innovators in a network, usually focus on the strong ties and weak ties within network [22].

Study of knowledge base and properties of embeddedness about what influence they have on performance show a tendency toward contingency. Kang and An [23] proposed that structural embedding is beneficial for firms in quantity of resources, while relational embedding benefits firms obtaining better resources. Characteristics of network have complex influence on performance $[24,25]$. This study attempts to investigate the embedding path selection of firms under different knowledge bases through comparative case studies.

\section{Case study}

\subsection{Sample and data collection}

This paper involves the selection of strategies for external network embedding based on the internal knowledge base of the enterprise, selecting comparative case study as study method as which is a question of know-how. Of all the quality e-commerces in China, we chose typical and relatively mature ones as case firms: YANXUAN and YOUPIN, who both 
stablished recognizable brand styles while of distinctly different knowledge base. The basic information is as follows.

The data sources for this paper are mainly from e-commerce platform websites and disclosures, reports and interviews collected from the Internet.

\subsection{YANXUAN}

This paper involves the selection of strategies for external network embedding based on the internal knowledge base of the enterprise, selecting comparative case study as study method as which is a question of know-how. Of all the quality e-commerces in China, we chose typical and relatively mature ones as case firms: YANXUAN and YOUPIN, who both stablished recognizable brand styles while of distinctly different knowledge base. The basic information is as follows.

YANXUAN as for the upstream of the value chain, YANXUAN adopts a mechanism called ODM buyer, to eliminate intermediate agents and to exert control over raw materials, production, QA and post-sale. The buyers select and contract excellent ODMs, especially manufacturers of top-tier international brands including that of Muji, Uniqlo, Samsonite, Hermes, Shiseido, CK, Nine West, Armani, Ralph Luaren, Chloe, Timberland, Fendi, Stoneline, Coach, HUGO BOSS, Under Armour.

In the midstream, YANXUAN utilizes flexible supply chain to cope with expanding categories. Within six mouthes from the launch of YANXUAN, its products include nine primary categories, 52 subcategories and 592 SKUs (Stock Keeping Unit), with is already wide coverage compared to general start-up e-commerce. One year later, SKUs climbed to over 10000 in a surprising speed. Unlike other large e-commerce" "space for time" solution of dense warehousing network, YANXUAN's flexible supply chain subdivides production plans into batches of smaller quantity. The launch of new products firstly commissioned a few batches, additional orders were adjusted sensitively according to the front-line sales volume. In an emerging of hot cake, it can also leverage control over supplier to fully utilize the production line and meet market demand timely.

From the sales side of the platform, YANXUAN cultivates the user group with the brand concept of "good life, not so expensive". As Walsh and Mitchell [26] argued, with the introduction of high quality labeled private merchandise, the confusion proneness associated with quality and emotions have significant impact on marketplace. By combining the user group portraits of NetEase Open Class and NetEase Cloud Music, YANXUAN targets its core user group at people aged 20-35 years old who seek to improve their quality of life but have limited purchasing power and define the brand style as a mid-range brand rich in artistic temperament, pursuing sophistication and advocating lifestyle aesthetics.

\subsection{YOUPIN}

YOUPIN intervenes in the upstream supply chain through investment and incubation. Backed on Xiaomi's mobile phone and IOT (Internet of Things), which has been the largest smart hardware platform worldwide, YOUPIN incorporates cooperative enterprises into the Xiaomi ecological chain, exerting values and participating in controlling design concepts, product definition, industrial design and other aspects.

YOUPIN differ from other quality e-commerces mainly in three principles of investment and incubation. Firstly, it cultivates ODMs by exporting enterprise management methodology and product development methodology, providing resources like channels, clients and even supply chain and moreover, values. Secondly, it has skin in the game with ecosystem companies through equity participation but not holding in order to maintain the combativity and innovation of startup teams. Finally, manufacturer can compete with 
products of YOUPIN. As Hoch and Banerji [27] proposed, private label goods should complement, not replace, the manufacturer's brand; that the right choice is for retailers to offer high quality and relatively low prices; and that private labels should try to avoid faceto-face competition with manufacturer-branded goods. Typical example is Huami, being the world's leading wearable maker, differentiating its main product AMAZFIT series from Xiaomi bracelets. Most different from YANXUAN, YOUPIN strives to support manufacturers in establishing their own independent brands, and the eco-friendly Huami, Zmi, Yeelight, Smartmi, Aqara, etc are already at the forefront of their respective industries. At the horizontal platform level, YOUPIN takes the lead in getting manufacturers to support reciprocally. Zmi, after becoming a leader in the mobile power industry, gradually provides battery for other ecological enterprises and help them improve power management solutions, getting stable customers in return.

\subsection{Knowledge base}

This paper, specific to the study of quality e-commerces, illustrated the knowledge base as primarily the ability to leverage its own brand resources and select manufacturers as well as products. This paper argues that YANXUAN is superior in terms of knowledge base breadth, while YOUPIN advanced in knowledge base depth.

As NetEase, the parent company of YANXUAN, has accumulated experience in grasping user groups, Internet marketing and establishing brand tone through its community-based products such as open classes and music while lacking experience about goods. On the other hand, the ability to select products need to be more proficient in the mastery of the manufacturing field, YOUPIN's knowledge from Xiaomi of the field of technology products has a more advantageous, more competitive than YANXUAN of the household merchandise.

\subsection{Embeddedness.}

YANXUAN adopted an embedding strategy that was first structural then relational, but did not achieve relational embedding successfully. After scaling back operations, YANXUAN still has far more SKUs on display than its competitors. In spite of strong supply chain management capabilities, the relationship between YANXUAN and ODM manufacturers stays in the contract.

The rapid expansion of the product system makes YANXUAN quickly occupy the central position of the ODM network, but the speed of experience accumulated by the category team can't keep up with the speed of SKU expansion, and can't rely on the relationship established with manufacturers to achieve complementary experience, the control of suppliers is insufficient. In addition, the product itself is neglected and the quality control capability is lost. Limit to contractual relationship, YANXUAN cannot control the manufacturer's R\&D activities, and ODM only provides homogeneous products according orders, which to some extent constraints the manufacturer's ability to stimulate innovation.

YANXUAN manages suppliers and a large number of SKUs through Tongzhou, an intelligent cloud collaboration platform for suppliers, which enables sharing of raw material stocking plans, production progress, inventory sharing, standardized quotation process, raw material price reference, as well as supplier optimization and assessment based on the above functions to improve the daily management of suppliers' sales. Tongzhou enables YANXUAN get in touch with ODMs as many as it want. Despite the brand's clear style, there is not too strong a definition of the user group. YANXUAN has opened a product recommendation of styles from Japan, France, Thailand, New Zealand, Vietnam, and Korea, and works with a large number of professional designers and design companies at home and abroad. 
YOUPIN, on the other hand, chose a relational to structural embeddedness strategy. About three quarter of the suppliers on YOUPIN come from Xiaomi or its ecosystem companies, and YOUPIN has established close ties with them in many ways, including R\&D, patents, sales, QA, inventory, logistics, accounting processing, and IOT ecology etc.

Constrained by the brand tone of the Xiaomi brand, it is difficult to expand consumer base and find added value in terms of emotional value. In the face of surging demand, YOUPIN is incapable of expanding its subcategories with guaranteeing quality.

Though YOUPIN's initial brand position of pursuing cost-effective and IOT ecology makes its consumer groups solid but difficult to expand, forcing the ecological chain companies to try untouched high-end market of YOUPIN itself, forming a virtuous cycle. Successful examples includ Huami's Amazfit and Zmi's Zmi 10 etc.

Through a comparative study of the above cases, this paper suggests that the path of embedding strategy should take into account the internal knowledge base of the platformtype enterprises in this paper, enterprises of which the breadth of the knowledge base is wider and lack in depth should adopt a structured strategy, focusing on relational embedding strategy timely; on the other hand, enterprises of which knowledge base is with great breadth and insufficient depth should adopt a relational strategy, gradually structured embedding strategy, instead of a single, consistent embedding strategy.

\section{Conclusion}

This study, based on a comparative case study of YANXUAN and YOUPIN, argues that the selection of embedded strategies for SMEs based on the internal knowledge base of the enterprise has some implications for the selection of network strategies for SMEs.

Various paradigms between OEM, ODM and OBM are emerging, such as many new formats like "new retail". The relationship between enterprise knowledge heterogeneity and its linkages also needs to be further discussed. The pursuit of differentiation among competing firms, the study of their development direction can more effectively reflect the dynamic and contingent characteristics of innovation network research than focusing merely on performance.

The case subjects selected for this paper are small, the research model used may be oversimplified, and future research will require a larger sample of data.

\section{Acknowledgements}

This research was financially supported by the Humanities and Social Sciences Fund Project of the Ministry of Education of China (No.20YJCZH066), the Beijing Municipal Social Science Fund (No.16GLC041), the National Nature Science Foundation of China for Youth (No.71503011), the Beijing Municipal Young Top-Notch Talent Funding Program (2017000026833ZS02) and the Basic Scientific Research Business Expenses Project of Beijing Municipal Education Commission (No.110052971921072).

\section{References}

1. H. Chesbrough. The logic of open innovation: managing intellectual property, California management review, 45, 33-58 (2003)

2. K. Akamatsu, A historical pattern of economic growth in developing countries, The developing economies, 1,3-25, (1962) 
3. D.Kale, L. Steve Little. From imitation to innovation: the evolution of R\&D capabilities and learning processes in the Indian pharmaceutical industry, Technology Analysis \& Strategic Management, 19, 589-609 (2007)

4. F. Wang, K. Chen. Do product imitation and innovation require different patterns of organizational innovation? Evidence from Chinese firms, Journal of Business Research. 106, 60-74 (2020)

5. M. Hobday. East Asian latecomer firms: learning the technology of electronics, World development, 23, 1171-1193 (1995)

6. K. Lee. Making a technological catch - up: Barriers and opportunities, Asian Journal of Technology Innovation, 13, 97-131 (2005).

7. W. Chu. Can Taiwan's second movers upgrade via branding, Research Policy, 38, 10541065 (2009)

8. J. Weerawardena. The role of marketing capability in innovation-based competitive strategy, Journal of Strategic Marketing, 11, 15-35 (2003)

9. A. Kaleka, A. M. Neil. How marketing capabilities and current performance drive strategic intentions in international markets, Industrial Marketing Management, 78,108121 (2019)

10. F. Lee. Recombinant uncertainty in technological search, Management Science, 47, 117132 (2001)

11. S. Yayavaram, W. Chen. Changes in firm knowledge couplings and firm innovation performance: the moderating role of technological complexity, Strategic Management Journal, 36, 377-396, (2015)

12. S. Moorthy, D. E. Polley. Technological knowledge breadth and depth: performance impacts, Journal of Knowledge Management, 14, 359-377 (2010).

13. S. Awate, M. M. Larsen, R. Mudambi. EMNE catch - up strategies in the wind turbine industry: is there a trade - off between output and innovation capabilities, Global Strategy Journal, 2 205-223 (2012)

14. Subramanian, Annapoornima M., Wang Bo, and Chai Kah-Hin. "The role of knowledge base homogeneity in learning from strategic alliances." Research policy 47 (1) 158-168 (2018)

15. K. Z. Zhou, C. B. Li. How knowledge affects radical innovation: knowledge base, market knowledge acquisition, and internal knowledge sharing, Strategic Management Journal, 33, 1090-1102 (2012)

16. G. Carnabuci, E. Operti. Where do firms' recombinant capabilities come from? Intraorganizational networks, knowledge, and firms' ability to innovate through technological recombination, Strategic Management Journal, 34, 1591-1613, (2013)

17. J. Krafft, Q. Francesco, P. P. Saviotti. Knowledge characteristics and the dynamics of technological alliances in pharmaceuticals: empirical evidence from Europe, US and Japan, Journal of Evolutionary Economics. 24, 587-622 (2014)

18. T. Lou, T. Jie. Mining structural hole spanners through information diffusion in social networks, Proceedings of the 22nd International Conference on World Wide Web. 2013.

19. M. A. Schilling, C. C. Phelps, Interfirm collaboration networks: the impact of large-scale network structure on firm innovation, Management Science. 53, 1113-1126 (2007)

20. T. Caner, S. Jing, E. P. John. When a firm's centrality in R\&D alliance network is (not) the answer for invention: the interaction of centrality, inward and outward knowledge transfer, Journal of Engineering and Technology Management. 33, 1113-1126 (2014) 
21. N. Lahiri, N. Sriram. Vertical integration, innovation, and alliance portfolio size: implications for firm performance, Strategic Management Journal. 34, 1042-1064 (2013)

22. M. Tortoriello, R.R. Marco, B. McEvily. Bridging the knowledge gap: the influence of strong ties, network cohesion, and network range on the transfer of knowledge between organizational units, Organization Science. 23, 1024-1039 (2012).

23. S. Kang, L. An. Network embedding, innovation ability and knowledge power: a perspective based on global value chain, Science of Science and Management of S.\&.T. 40, 1-12 (2019)

24. V. Gilsing, N. Bart. Density and strength of ties in innovation networks: an analysis of multimedia and biotechnology, European Management Review. 2, 179-197 (2005)

25. J. Zhang. Facilitating exploration alliances in multiple dimensions: the influences of firm technological knowledge breadth, R\&D Management. 46, 159-173 (2016)

26. G. Walsh, V. W. Mitchell. The effect of consumer confusion proneness on word of mouth, trust, and customer satisfaction, European Journal of Marketing, 44, 838-859 (2010)

27. S. J. Hoch, S. Banerji. When do private labels succeed, MIT Sloan Management Review. 34 (1993) 